hospital intubation without drugs was hopeless, ${ }^{3}$ but we found that $8 \%$ of patients survived. The number was small, with the lower limit of the confidence interval of $0.2 \%$ just equal to the mean survival reported by the helicopter service.

Anaesthesia and intubation can be complicated by head and facial injuries, cervical fractures, risk of oesophageal intubation, aspiration, circulatory deterioration, and increased intracerebral pressure. The environment out of hospital is different from in hospital and support and resources are limited. We question whether anaesthesia and intubation of trauma patients can be mastered and routine be maintained by ambulance personnel.
Contributors: Both authors designed the study, did the statistical analysis, and wrote and revised the manuscript. CCSH collected the data. EFC is guarantor.

Funding: No additional funding.

Competing interests: None declared.

1 Sethi D, Kwan I, Kelly AM, Roberts I, Bunn F (on behalf of the WHO PreHospital Trauma Care Steering Committee). Advanced trauma life support training for ambulance crews. Cochrane Library. Issue 2. Oxford: Update Software, 2003: CD003109.

2 Liberman M, Mulder D, Sampalis J. Advanced or basic life support for trauma: meta-analysis and critical review of the literature. J Trauma 2000;49:584-99.

Lockey D, Davies G, Coats T. Survival of trauma patients who have prehospital tracheal intubation without anaesthesia or muscle relaxants: observational study. BMJ 2001;323:141

(Accepted 13 May 2003)

\title{
Risk of adenocarcinoma in Barrett's oesophagus: population based study
}

\author{
Liam Murray, Peter Watson, Brian Johnston, James Sloan, Inder Mohan Lal Mainie, Anna Gavin
}

Northern Ireland Cancer Registry, Department of Epidemiology and Public Health, Public Health, of Belfast, Belfast BT12 6BJ

Anna Gavin director

Liam Murray senior lecturer in epidemiology

Royal Hospitals Trust, Belfast BT12 6BA

Peter Watson consultant gastroenterologist Brian Johnston consultant gastroenterologist

James Sloan

consultant pathologis

Ulster Hospital,

Dundonald, Belfast BT16 1RB

Inder Mohan Lal

Mainie

specialist registrar in gastroenterology

Correspondence to: L Murray

l.murray@qub.ac.uk

BMJ 2003;327:534-5
Endoscopic surveillance of Barrett's oesophagus is now routine. ${ }^{1}$ Cost effectiveness depends on the risk of oesophageal adenocarcinoma. ${ }^{2}$ The magnitude of this risk is unclear because most previously published studies were small and inconclusive. ${ }^{3}$ Except for one, ${ }^{4}$ these studies were not population based but investigated patients at one or more centres. Selection bias or the effect of common losses to follow up were not assessed. ${ }^{5}$ We investigated the risk of oesophageal malignancy in a large cohort of unselected patients with Barrett's oesophagus in Northern Ireland, where all incident cancers are routinely identified.

\section{Participants, methods, and results}

We examined the pathology reports relating to all oesophageal biopsies in Northern Ireland between January 1993 and December 1999. We included every adult identified within Northern Ireland (population 1.7 million) as having oesophageal columnar epithelium. We excluded biopsies taken at the oesophagogastric junction.

We defined Barrett's oesophagus as the presence of columnar metaplasia in the oesophagus irrespective of whether Barrett's mucosa was reported (although we used this fact to further classify the biopsies as "macroscopic Barrett's oesophagus" or otherwise). We did not use data on segment length because it was often absent from reports. We subdivided biopsies finding Barrett's oesophagus further if the pathologist specifically stated that specialised intestinal metaplasia or goblet cells were definitely present or absent. We excuded malignant biopsies.

We identified patients in the cohort and followed them up for death and oesophageal malignancy (oesophageal adenocarcinoma and histologically unspecified oesophageal carcinomas or malignancies) until the end of 2000 by matching with death records from the Registrar General's Office and the Northern Ireland Cancer Registry's database of incident cancers.
We excluded oesophageal malignancies diagnosed within six months of the initial biopsy. We identified all patients in Northern Ireland with Barrett's oesophagus who had an oesophagectomy or ablative treatment for high grade dysplasia between January 1993 and December 2000. We calculated person years of follow up until diagnosis of the malignancy, death, or 31 December 2000. We estimated confidence intervals from the Poisson distribution.

Between 1993 and 1999, of 15670 oesophageal biopsies, 4955 (from 2969 patients) met our criteria for Barrett's oesophagus (table). The mean follow up was 3.7 (range 1 to 8 ) years, with 11068 person years of follow up. We found 29 oesophageal malignancies in the cohort. Four patients had an oesophagectomy for high grade dysplasia and two had ablative laser treatment. Oesophageal malignancy was $0.26 \%(0.18 \%$ to $0.38 \%)$ a year overall and $0.4 \%(0.26 \%$ to $0.59 \%)$ a year for patients with specialised intestinal metaplasia. The malignancy rate in men was 2.5 times that in women. Only for men older than 70 with specialised intestinal metaplasia was incidence greater than $1 \%$ per year.

\section{Comment}

Patients with Barrett's oesophagus are at low risk of oesophageal adenocarcinoma, and this risk is almost exclusively in patients with specialised intestinal metaplasia. Surveillance of patients with Barrett's oesophagus at a risk of malignant transformation of $1 \%$ per year may be cost effective, ${ }^{2}$ but only men aged 70 or more are at this risk, and limiting surveillance to them would miss two thirds of cancers. The length of follow up in our study was brief, but up to eight years after diagnosis we found no increased risk of malignancy with time (data available from authors).

Robust methods for stratifying risk and targeting surveillance in Barrett's oesophagus are needed. Although we did not use specific protocols for 
Oesophageal malignancies (adenocarcinoma and histologically unspecified carcinoma or malignancy) in a cohort of patients with Barrett's oesophagus in Northern Ireland, 1993-9

\begin{tabular}{|c|c|c|c|c|}
\hline & No of patients & $\begin{array}{l}\text { No of oesophageal } \\
\text { malignancies }\end{array}$ & $\begin{array}{c}\text { Follow up } \\
\text { (person years) }\end{array}$ & $\begin{array}{l}\text { Incidence of oesophageal } \\
\text { malignancies per } 100 \text { person } \\
\text { years of follow up }(95 \% \mathrm{Cl})\end{array}$ \\
\hline All patients & 2969 & 29 & 11068 & $0.26(0.18$ to 0.38$)$ \\
\hline Men & 1701 & 22 & 6230 & 0.35 (0.21 to 0.52$)$ \\
\hline Women & 1268 & 7 & 4838 & $0.14(0.06$ to 0.30$)$ \\
\hline \multicolumn{5}{|l|}{ Specialised intestinal metaplasia: } \\
\hline Present & 1670 & 26 & 6517 & $0.40(0.26$ to 0.59$)$ \\
\hline Absent & 545 & 1 & 1730 & $0.06(0$ to 0.32$)$ \\
\hline Unknown & 745 & 2 & 2821 & $0.07(0.01$ to 0.26$)$ \\
\hline \multicolumn{5}{|l|}{ Macroscopic Barrett's oesophagus: } \\
\hline Present & 1929 & 22 & 7470 & $0.29(0.18$ to 0.44$)$ \\
\hline Present with specialised intestinal metaplasia & 1300 & 21 & 5183 & $0.41(0.25$ to 0.62$)$ \\
\hline \multicolumn{5}{|l|}{ Dysplasia: } \\
\hline High grade & 19 & 3 & 64 & $4.69(0.97$ to 13.7$)$ \\
\hline Mild or moderate & 171 & 7 & 648 & $1.08(0.43$ to 2.23$)$ \\
\hline \multicolumn{5}{|l|}{ Patients with specialised intestinal metaplasia } \\
\hline \multicolumn{5}{|l|}{ Men aged (years) } \\
\hline$<50$ & 243 & 1 & 965 & $0.10(0$ to 0.58$)$ \\
\hline$\geq 50$ & 789 & 19 & 2979 & $0.64(0.38$ to 1.00$)$ \\
\hline$\geq 60$ & 547 & 16 & 2030 & 0.79 (0.45 to 1.28$)$ \\
\hline$\geq 70$ & 269 & 9 & 882 & $1.02(0.47$ to 1.94$)$ \\
\hline$\geq 80$ & 76 & 3 & 199 & 1.51 (0.31 to 4.42$)$ \\
\hline \multicolumn{5}{|l|}{ Women aged (years) } \\
\hline$<50$ & 71 & 0 & 297 & $0(0$ to 0.24$)$ \\
\hline$\geq 50$ & 567 & 6 & 2275 & $0.26(0.1$ to 0.57$)$ \\
\hline$\geq 60$ & 467 & 6 & 1826 & 0.33 (0.12 to 0.72$)$ \\
\hline$\geq 70$ & 305 & 3 & 1178 & $0.25(0.05$ to 0.74$)$ \\
\hline$\geq 80$ & 104 & 0 & 360 & 0 (0 to 1.03$)$ \\
\hline
\end{tabular}

oesophageal biopsy, because the data are from routine clinical practice, our findings may have more relevance for standard care than previous studies.

We thank Colin Fox, Richard Middleton, Tom Wylie, and the tumour verification officers of the Northern Ireland Cancer Registry for help processing pathology records; the administrative, medical, and pathology staff of local healthcare trusts; the staff of the Directorate of Information Services for help compiling the Northern Ireland Barrett's register; and Deirdre Fitzpatrick and Chris Patterson for statistical advice.

Contributors: LM had the idea for the study, constructed the register, analysed the data, and wrote the intial draft. AG, PW, BJ, and JS, designed the study and interpreted the data. IMLM helped construct the register. All authors commented on draft manuscripts. LM is guarantor.

Funding: Ulster Cancer Foundation.
Competing interests: None declared.

Ethical approval: Research ethics committee, Queen's University Belfast.

1 Gross CP, Canto MI, Hixson J, Powe NR. Management of Barrett's esophagus: a national study of practice patterns and their cost esophagus: a national study of practice pate
implications. Am J Gastroenterol 1999:94:3440-7.

2 Provenzale D, Schmitt C, Wong JB. Barrett's esophagus: a new look at surveillance based on emerging estimates of cancer risk. Am J Gastroenterol 1999;94:2043-53.

3 Shaheen NJ, Crosby MA, Bozymski EM, Sandler RS. Is there publication bias in the reporting of cancer risk in Barrett's esophagus. Gastroenterology 2000;119:333-8.

4 Conio M, Cameron AJ, Romero Y, Branch CD, Sschleck CD, Burgart LJ, et al. Secular trends in the epidemiology and outcome of Barrett's esophagus in Olmsted County, Minnesota. Gut 2001;48:304-9.

5 Macdonald CE, Wicks AC, Playford RJ. Final results from 10 year cohort of patients undergoing surveillance for Barrett's oesophagus: observaof patients undergoing surveillance
tional study. BMJ 2000;321:1252-5.

(Accepted 3 July 2003)

\section{One hundred years ago}

\section{Wage-earning school children}

A very interesting report on wage-earning school children has been prepared for the Manchester Education Committee. Inquiries have been made from the head teachers of the 159 elementary schools in the city on the employment of children out of school hours. Over 3,000 school children are at work, and their hours of labour range from a minimum of 1 a week to a maximum of $68^{1 / 4}$. More than 200 work from 30 to 40 hours per week, about 64 from 40 to 50 hours, 9 from 50 to 60 hours, and 1 child of 12 years is reported as working on a farm for no fewer than $68^{1 / 4}$ hours per week. The occupations in which the majority of the children are engaged, and those working the longest hours, are in vending and distributing newspapers, in barbers' shops, errand boys in retail shops, in the milk business, and to a lesser degree in domestic work of various kinds. One child of 6 years of age is said to be engaged 20 hours a week in selling newspapers.
Amongst about 20 children of 7 years old 1 is employed 27 hours a week, also in the sale of newspapers, and another runs errands for 26 hours a week. Other children of this age work 17, 12, and 8 hours and under. There are from 40 to 50 children of 8 years of age working for 25, 24, and 21 hours and less. There are about 120 children of 9 years of age engaged, and 1 of them at least works 29 to 30 hours a week. The rest of the children are from 10 to 13 years of age. Curiously enough the number at 14 years of age is inconsiderable. The wages of the children do not seem to bear any proportion to the number of working hours. The boy who is said to work on a farm for $68^{1 / 4}$ hours a week receives 3s. $6 \mathrm{~d}$. and his keep, but finds his own shoes. The sale of newspapers appears most profitable, and some of the children's earnings range from $7 \mathrm{~s}$. to 11 s. per week.

(BMJ 1903;ii:1164) 